\section{SOMA: NOT SO DIVINE}

\section{Jean Mulholland ${ }^{1}$}

\begin{abstract}
An examination of the method of preparation and the properties of the drug, Soma, used in the sacrificial rituals of the Vedic religion since before $1500 \mathrm{BC}$, proves that R. Gordon Wasson was wrong. Soma was not a 'divine' mushroom. Soma is more likely to have been a plant part, such as seeds, roots, leaves or a substance, such as an oleo-resin, prepared from the sap of a plant, small or large.
\end{abstract}

This paper incorporates some of the pertinent points made on this subject by the author in a previous publication (Mulholland, 1980).

\section{Introduction}

When the Aryan people first came to northern India about 3000 years ago, they brought with them the Vedic religion. The focus of the Vedic religion was the sacrifice. The essence of the sacrifice was Soma. There has long been debate about the identity and the source of the drug, Soma, used in this sacrificial ritual.

The sacrifice included the offering of Soma as a libation to the gods, by pouring it on the fire, where it burnt like incense, rising as an aromatic vapour to

${ }^{1}$ Honorary Research Associate National Thai Studies Centre Australian National University the heavens. Soma, mixed with milk, sometimes with curds or barley, was taken by the priests and participants in the ritual. It had a highly stimulating and exhilarating effect. It was used three times a day, implying an abundance of supply. It was made at the ceremony, immediately prior to the sacrifice, so it was not a product of fermentation, such as alcohol. Nor was it a narcotic, such as opium (Mulholland, 1980:182).

The miracle of Soma, observed and recorded in the Rig-Veda by the priests, was its three forms. First, the crude Soma (of unknown provenance) was washed and crushed, releasing a volatile oil which could be seen floating on the surface of this liquid. Second, the oil was separated from the water and other debris by filtration through the wool and skin of a sheep; and third, a beverage was prepared by mixing the oil with milk, for human consumption.

\section{The supply of Soma}

Soma became unavailable to Indian worshippers long ago, and a substitute is now used. ${ }^{2}$ There appears to be no way that it can be identified from comparatively modern sources or use.

There could have been many reasons for the cessation of supply-drought or pestilence, war or disease, political or religious oppression. There might easily have been a temporary abandonment of the sacrifice.

${ }^{2}$ Personal communication. Professor A. L. Basham, Australian National University, 1974. 


\section{The translation of the Rig-Veda}

There is a great of repetition in the Rig$V e d a$. This seems to indicate that the compilers have included all available versions of the hymns, as occurs in other sacred Asian canons handed down, purportedly unaltered, for generations, such as Thai texts of Indian influence.

There are over a thousand hymns in the Rig-Veda, and 114 of these are included in Book 9. Most of the hymns of Book 9 concern Soma, its preparation and use in the Vedic sacrifice. The various steps in the preparation of the drug, Soma, are explained over and over again.

For this study, the English translation of the Rig-Veda by Ralph T. H. Griffith, The hymns of the Rgveda (RV), is used for consistency, as this was used in the earlier 1980 paper.

I hope, here, by further investigating what the verses actually convey to the reader, as far as can be ascertained, to be able, by adopting a scientific approach, to explain some more details of the preparation and properties of the Soma burnt, as incense, on the fires, and consumed by priests and others, in the Vedic sacrificial ritual.

\section{The purchase of Soma}

Where did the crude Soma come from? The hymns do not make it clear when they are referring to fact and when they are referring to ritual. Many authorities agree that it grew upon the mountains (Keith, 1970:169); (Blomfield, 1965:145); (Macdonell, n.d.: 78). Some interpret these phrases as referring to the ritual. Macdonell says 'Soma is in several passages said to grow or dwell on the mountains, but his true origin and abode are thought to be in heaven'. Most agree that it was connected with water. It is most likely that both 'mountains' and 'waters' refer to the ritual. The waters were those used to separate the oil from the crude Soma, and the mountain is the sheepskin filter suspended high above the vats of milk placed below to receive the drops of oil raining down.

How it was obtained is not stated, except for the ceremonial buying of the crude Soma during the performance of the ritual. It was there bought with Speech or in its place, with a young cow (Keith, 1971:128).

The purchase of Soma with a heifer is part of the ritual, not a description of the true way it was obtained (Jamison, 1996:120 ff.).

\section{The crude Soma}

Until Wasson became convinced that it was a mushroom, Soma was commonly thought to be a plant, and that the juice was extracted from the stalks or stems of the plants by crushing with stones. Consequently, most scholars interested in the identity of Soma search for a plant.

Surprisingly, nowhere in the Rig-Veda, nor in any of the Vedic literature, is a clear description of the Soma 'plant' or its parts to be found.

The reason why the Soma 'plant' and its 'stalks' are so hard to identify, and the reason why the names of its parts are never found, is that there probably 
was no 'plant'! Translators, believing that Soma was crushed out of the stems of a plant, provided the missing words when it seemed appropriate. This is understandable. Even so, the Sanskrit language allows for many interpretations, including, in this case, the possibility that the crude Soma, crushed with stones, might have been a oart or extract of a plant or tree.

It seems reasonable to believe that the crude Soma, which could have been a plant, might just as easily have been an oily substance or part derived from a plant. For example, the seeds of a member of the Umbelliferae; the dried oleo-resin of a member of the Burseraceae, and so on.

\section{The preparation of Soma}

In brief, a study of the Rig-Veda shows that first, the green-coloured, ${ }^{3}$ crude Soma was placed on a cowhide and cleaned by hand by washing with water. It was then crushed with stones in a wooden mortar, or in a similar fashion, and the resultant tawnycoloured fluid flowed along the conduit into the filter. Radiant, oily droplets of Soma could be seen, gleaming, floating on the surface, and the aroma rising up

${ }^{3}$ We cannot rely on the colour terms used in the Rig-Veda for an accurate description of the Soma in any of its forms. The word 'hari' can mean any reddish hue, from brown to yellow, from fresh coloured to green, and it is doubtful whether, at the time of the composition of the Rig-Veda, the Aryan people had exact words for green and yellow colours. See Berlin and Kay (1969).

from them could be smelt.
The filtration process assumed a magical quality. Soma is called Pavamana, self purifying, and its self purification occurred when the extracted liquid was filtered. The filter was an unshorn sheepskin, wool side up, or inside, if, as seems probable, the sheepskin was made into a bag, like a water bag. The oily extract was separated from the water and other matter by filtration, 'down Indra's throat', through the wool and skin of the sheepskin where the naturally occurring lanolin permitted the sweetened, ${ }^{4}$ oily substance to pass through, while the sheepskin remained impermeable to the water and other matter. The sheepskin could not have been used lying flat, because a container of some sort was necessary to hold the water and residue after the separation of the Soma oil through the skin. The bag was 'milked' by the hands of those preparing the Soma, just like someone milking a cow. They squeezed the oily drops through the skin. Sometimes they blew into the bag. ${ }^{5}$ Otherwise, most of the oil would have floated on top of the water and other residual matter lying in the bottom of the filter. It would have taken days for the oil to make its way through the fleece and the sheepskin.

This was not a simple process of straining the liquid from the residue of the crushed crude Soma. Such a process

\footnotetext{
${ }^{4} \mathrm{RV}, 9: 12: 1$. '...the Soma drops, exceeding rich in sweets.'; 9.63:16. 'Soma...most rich in sweets.'; 9.63:19. '...vvery sweet to taste.' ${ }^{5} \mathrm{RV}, 9: 1: 8$. '...they blow the skin musicianlike.'
} 
does not warrant the lengths to which the poets went to describe it. They were trying to convey a mystery which they could not explain. The liquid which emerged from the filter had purified itself. It had changed its colour and its texture. It was no longer tawny coloured, it was golden. It was no longer fast flowing and speckled with 'glistening particles, it emerged as oily drops.

The sparkling golden oil, bursting, like the sun, through the cloud-like fleece, fell noisily, like rain, into the vats of milk placed below. The milk in the vats, being already an emulsion, absorbed some of the oil, making it more palatable. Not all the oil combined with the milk, since the mixture glistened.

It was then drunk by the priests. The Soma was offered to the gods by casting some of it on the fire, where it obviously burnt, giving off its pleasant-smelling fumes. Clearly, it was used as incense! It is not quite so clear whether the oil used for burning as incense was mixed with milk. This seems improbable.

\section{Was Soma really a mushroom?}

Various attempts have been made to identify Soma. Wasson (1968) proposed that it was the mushroom, Amanita muscaria, an opinion that has always been questioned.

In his beautifully illustrated book Soma divine mushroom of immortality, Wasson (1968:11) announces...
'My candidate for the identity of Soma is Amanita muscaria (Fr. ex L.) Quel., in English the fly-agaric, the Fliegenpilz of the Germans, the mukhomor of the Russians, the fausse orange or tue-mouche or crapaudin of the French, the brilliant red mushroom with white spots familiar in forests and folklore throughout northern Eurasia'.

How did he arrive at this conclusion? It seems to have been by divine inspiration. It makes a good story. Many such guesses have been made, but Wasson's seems to have been accepted - without reason. Given the complete lack of evidence describing the crude Soma, from which the drug Soma was extracted, Wasson's method of identification could be applied to many substances.

In 1995, Professor Denis R. Benjamin, of the University of Washington, Seattle, published the most comprehensive text on mushrooms available since I first questioned R. Gordon Wasson's opinion that Soma was a mushroom. I am indebted to Professor Benjamin for his crucial contribution to my argument.

'In general, mushrooms have only small amounts of fats and oils, since most energy is stored in carbohydrates. The pharmacological effects of these mushrooms [Amanita muscaria] are due to muscimol and ibotenic acid. I would not expect these to be extracted in the lipid fraction, since they are water

soluble. Of course, there may be a variety of other compounds which also 
contribute to the biological effects and which have not yet been described.' ${ }^{6}$

Considering the above statement, and the scientific studies made of Amanita muscaria, which show that the known active ingredients are water soluble, andtaking into account that mushrooms do not, usually, contain large amounts 'of oils, it is highly unlikely that volatile oils would be found in Amanita muscaria or any other mushroom in sufficient quantities to be able to be extracted from them by the process described in the Rig -Veda. Even if there were a very small oil content, it would almost certainly not float on the water used to wash out the Soma, as described, since most volatile oils are slightly soluble in water, and the proportion of oil to water would need to be considerably larger for the two to be able to be separated by the process of filtration through the lanolin of the wool and skin of a sheepskin as described in the Rig$v e d a$. Also it is unlikely that a lipid soluble stimulant would be found in Amanita in useful quantities, since it was not detected in previous analysis.

\section{So, Wasson is wrong. Amanita muscaria} cannot be Soma. The active ingredients of Amanita muscaria, muscimol and ibotenic acid, are water soluble, and would not pass through the sheepskin filter, but would be retained, with the other debris, in the aqueous phase within the sheepskin bag.

\footnotetext{
${ }^{6}$ Professor Denis R. Benjamin, University of Washington, Seattle, personal communication, 12.6.97.
}

\section{Conclusion}

In my first investigation into the tantalizing question of the identity of Soma, I was prepared to accept that the crude Soma was a plant, but doubted that it was a mushroom. I am now convinced that it was neither.

In many places in the translations where the word 'plant' occurs in relation to the crude Soma, this term does not occur in the Sanskrit, but is understood by the translator! The term understood might have been more accurately 'Soma'? There are only a few occasions where 'plant' might possibly, but not necessarily, be the meaning intended. The same can be said for the word 'stalks'.

While the crude matter could have been a plant part, such as seeds bearing a volatile oil (but not a fixed oil) or volatile oil-bearing seed pods, roots, leaves, stalks and so on, it could equally have been an oleo-resin or oleo-gumresin, occurring as the dried exudate of a tree or shrub. Such substances, used as incense, have been of significant religious and mystic reputation in both European and Asian cultures for thousands of years. Many dried, volatile oil-bearing substances produced from plant parts, if crushed with water, can be reconstituted as a milky emulsion, like the original plant extract or sap before it hardens on drying.

${ }^{7}$ Personal communication, Ann Appleby Hazelwood, MA, who provided invaluable assistance relating to the interpretation of sections of the Sanskrit text, 1998. 
The obvious question to ask is, why go to such trouble to extract a volatile oil? The answer is that they knew no other way. Even though the Vedic priests had learnt to volatilise incense and send its essential oils to their gods in the heavens, they did not yet know the simple next step in the distillation process - how to collect the vapour.

\section{References}

Benjamin, Denis R.1995. Mushrooms: poisons and panaceas. New York: Freeman.

Departments of Laboratory Medicine and Pathology, University of Washington, Seattle, (personal communication).

Berlin, B., and P. Kay. 1969.Basic colour terms. Berkeley: University of California Press.

Bloomfield, M. The religion of the Veda.New York: AMS Press, reprint of 1908 edn.1969.

Griffith, Ralph T. H., trans.1973. The hymns of the Rgveda.Ed., J.L.Shastri.Delhi: Motilal Banarsidass, New revised edn
Jamison, Stephanie W. Sacrificed wifel sacrificer's wife. Women, ritual, and hospitality in ancient India.New York, Oxford University Press, 1996.

Keith, A. B.1970. The religion and philosophy of the Veda and Upanishads. The Harvard Oriental Series, vol. 31. Delhi: Motilal Banarsidass,

(Translation). 1971. RigvedaBrahmanas.

The Harvard Oriental Series, vol. 25. 1st Indian reprint edn. Delhi: Motilal Banarsidass.

Macdonell, A. A. (Translation) Hymns from the Rigveda. Calcutta: Association Press, (no date).

Mulholland, Jean.1980.'Soma: an attempt to classify the plant and the drug.' Social Science \& Medicine 14B. 181-184.

Wasson, R. Gordon. 1968. Soma divine mushroom of immortality. The Hague: Mouton. 